\title{
Ön çapraz bağ rekonstrüksiyonu sonrası takip ve rehabilitasyon
}

\author{
Follow-up and rehabilitation after anterior cruciate ligament reconstruction
}

\author{
Gülcan Harput ${ }^{1}$, İbrahim Bozkurt² ${ }^{2}$ Durmuş Ali Öçgüder ${ }^{2}$ \\ ${ }^{1}$ Hacettepe Üniversitesi, Fizik Tedavi ve Rehabilitasyon Fakültesi, Ankara \\ ${ }^{2}$ Ankara Şehir Hastanesi, Ortopedi ve Travmatoloji Kliniği, Ankara
}

Ön çapraz bağ (ÖÇB) rekonstrüksiyonu sonrası rehabilitasyonun amacı, hastayı güvenli bir şekilde ve yeterli diz fonksiyonu ile yaralanmadan önceki fiziksel aktivite seviyesine ulaştırmaktır. Aslında ÖÇB rüptürü olan hastalara ameliyat öncesi rehabilitasyon planlanarak ameliyat sonrası dönemdeki fonksiyonel performans üzerine katkı sağlanabilir. ÖÇB rekonstrüksiyonu sonrası ilk dört hafta greftin en zayıf olduğu dönemdir. Dolayısıyla rehabilitasyon sırasında egzersiz seçiminde greftin iyileşme ve gelişme süreci göz önünde bulundurulmalıdır. Erken eklem hareket açıklığının kazanılması önemlidir. Eklem hareket açıklığının artırılması ağrının azalmasına, kıkırdağın homeostazisini düzenlemeye ve patellofemoral eklem problemlerinin engellenmesine katkı sağlar. İzole ÖÇB rekonstrüksiyonundan sonra hastaların ekstremitesine tam ağırlık vermesi önerilmektedir. Kuvvetlendirme egzersizlerine cerrahi sonrası 1. günde başlanır. Kuadriseps inhibisyonu ÖÇB rekonstrüksiyonu sonrası en çok uğraşılan problemdir. İyi bir rehabilitasyon ile ÖÇB rekonstrüksiyonu sonrası spora dönüş oranı 1. yılda yaklaşık \%50'dir. ÖÇB rekonstrüksiyonu sonrası spora dönüşe objektif performansa dayalı testler (kas kuvveti, denge, sıçrama), subjektif skorlar (diz fonksiyonu ve kinezyofobiyi değerlendiren anketler) ve klinik muayene (laksite, ağrı, ödem vb.) ile karar verilmelidir.

Anahtar sözcükler: ön çapraz bağ rekonstrüksiyonu; rehabilitasyon; spora dönüş
The purpose of rehabilitation after anterior cruciate ligament $(A C L)$ reconstruction is to bring the patient to the level of physical activity before injury, safely and with adequate knee function. In fact, pre-operative rehabilitation can be planned for patients with ACL rupture and contribution can be made to functional performance in the post-operative period. The first 4 weeks after ACL reconstruction is the weakest graft period. Therefore, during rehabilitation, the healing and development process of the graft should be considered. It is important to gain an early joint range of motion. Increasing the range of motion helps to reduce pain, regulate cartilage hemostasis and prevent patellofemoral joint problems. After isolated ACL reconstruction, it is recommended that patients put full weight on their limbs. Strengthening exercises are started on the first day after surgery. Quadriceps inhibition is the most common problem after $A C L$ reconstruction. The rate of return to sports after $A C L$ reconstruction with good rehabilitation is approximately $50 \%$ in the first year. After $A C L$ reconstruction, decision-making should be made with objective performance based tests (muscle strength, balance, jump), subjective scores (questionnaires evaluating knee function and kinesiophobia) and clinical examination (laxity, pain, edema, etc.).

Key words: anterior cruciate ligament reconstruction; rehabilitation; return to sports

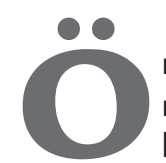

n çapraz bağ (ÖÇB) rekonstrüksiyonu sonrası rehabilitasyonun amacı, hastayı güvenli bir şekilde ve yeterli diz fonksiyonu ile yaralanmadan önceki fiziksel aktivite seviyesine ulaştırmaktır. ${ }^{[1]}$ ÖÇB rekonstrüksiyonu sonrası rehabilitasyon en az altı ay sürmekle birlikte hastanın ihtiyacına göre spora dönüş aşamasına kadar rehabilitasyon devam etmelidir. Rehabilitasyon, cerrahide kullanılan grefte, eşlik eden diğer yaralanmalara ve tamirlere, hastanın yaşına ve fiziksel aktivite seviyesine göre değişiklik göstermektedir. ${ }^{[2,3]}$ Hamstring tendon otogreftinde ve allogreftte rehabilitasyon patellar tendon (kemik-tendon-kemik) otogreftine göre daha kontrollü ve yavaş ilerlemelidir. Bununla birlikte sporcularda rehabilitasyon sedanter bireylere göre daha agresif ilerlemelidir.

ÖÇB rekonstrüksiyonu sonrası cerrahinin ve rehabilitasyonun başarısını negatif etkileyen bir takım faktörler vardır. ${ }^{[3]}$ Bunlar:

- İletişim adresi: Prof. Dr. Durmuş Ali Öçgüder, Ankara Şehir Hastanesi, Ortopedi ve Travmatoloji Kliniği, Üniversiteler Mahallesi 1604, Cadde No: 9 , Çankaya, Ankara Tel: 0505 - 4578788 e-posta: aliocguder@yahoo.com

- Geliștarihi: 6 Nisan $2020 \quad$ Kabul tarihi: 21 Nisan 2020 
1. Hastanın yaşının büyük olması

2. Hastanın rehabilitasyona katılımının düşük olması

3. Hastanın yaralanmadan önceki fiziksel aktivite seviyesinin düşük olması

4. Hastanın beden kitle indeksinin yüksek olması $\left(\mathrm{BKI}>30 \mathrm{~kg} / \mathrm{m}^{2}\right)$

\section{Eklem kıkırdak hasarının varlığı}

6. Cerrahi öncesi diz eklem hareketinde kısıtlılık, kas atrofisi, effüzyon ve ağrının varlığı

7. Yaralanmadan cerrahiye kadar geçen sürenin uzun olması

8. Sigara içiciliği

9. Hastanın ameliyat öncesi rehabilitasyon almaması

Ameliyat öncesi rehabilitasyonun ameliyat sonrası dönemdeki fonksiyonel performans üzerine önemli katkısı bulunmaktadır. ${ }^{[4]}$ Cerrahi öncesi hastanın ekstansiyon eklem hareket kaybının olması cerrahi sonrası ekstansiyon hareket açıklığının kazanılamamasında birincil rol oynamaktadır. Kuadriseps kas kuvvetinde \%20'den fazla kaybın olması cerrahi sonrası IKDC (International Knee Documentation Committee) ve KOOS (Knee Injury \& Osteoarthritis Outcome Score) değerlerinin düşük olmasına neden olduğu gösterilmiştir. ${ }^{[5]} \mathrm{Bu}$ nedenle, cerrahi öncesi en az altı haftalık rehabilitasyonla diz fonksiyonlarının normalize edilmesi ve hastanın cerrahiye hazırlanması önemlidir. ${ }^{[2]}$

ÖÇB rekonstrüksiyonu sonrası patellar tendon greftinin tünel içine kaynaşması 6-8 hafta, hamstring tendon greftinin ise 8-12 hafta almaktadır. Cerrahi sonrası ilk dört hafta greftin en zayıf olduğu evredir. ${ }^{[6]}$ ilerleyen haftalarda revaskülarizasyon ve matürasyon süreci ile greftin gerilim kuvveti artar. ${ }^{[6]}$ Bu nedenle, rehabilitasyon protokolünde egzersiz seçiminde greftin iyileşme ve gelişme süreci göz önünde bulundurulmalıdır.

ÖÇB rekonstrüksiyonu sonrası rehabilitasyon farklı evrelere bölünerek zaman temelli planlansa da, bu evreler her hasta için aynı zamanlama ile olmamaktadır. Bu nedenle rehabilitasyon bireye özgü olarak şekillendirilmelidir.

\section{ENFLAMASYONUN KONTROLÜ}

Cerrahi sonrası erken dönemde birincil hedef enflamasyonu kontrol altında tutmak, normal eklem hareket açıklığının kazanımını ve kuadriseps kas kontrolünü sağlamaktır. Enflamasyonun kontrol altına alınması, kuadriseps inhibisyonunu önlemede, tam diz ekstansiyonunun kazanımında ve erken ağırlık aktarma toleransında önemli rol oynamaktadır. Ödemin ve ağrının kontrolünde soğuk uygulama, elevasyon, bandajlama ve kinezyo-bantlama yararlı olabilmektedir. ${ }^{[7]}$

\section{NÖROMUSKÜLER ELEKTRIKK STIMÜLASYONU (NMES)}

Kuadriseps inhibisyonu ÖÇB rekonstrüksiyonu sonrası en çok uğraşılan problemdir. ${ }^{[8]}$ Kuadriseps kasının eski gücünü kazanabilmesi (re-edükasyonu) için nöromusküler elektrik stimülasyonuna cerrahi sonrası ilk gün başlanır. ${ }^{[9]}$ Terminal izometrik egzersizi $\left(0^{\circ}-30^{\circ}\right)$ ve düz bacak kaldırma egzersizleri elektrik stimülasyonuyla birlikte kuadriseps kas aktivitesini artırmak için kullanılabilir. İstemli kas aktivitesi yeterli düzeye eriştiğinde NMES sonlandırılır. Bu süre genelde ameliyat sonrası 4. hafta sonudur.

\section{DiZLIK KULLANIMI}

ÖÇB rekonstrüksiyonundan sonra dizlik kullanımı tartışmalıdır. Dizlik kullanan ve kullanmayan hastaların uzun dönem fonksiyonel performanslarına bakıldığında herhangi bir farklılık görülmemiştir.[10] Maliyeti yüksek bir ekipman olduğundan, kuadriseps kas kontrolü yetersiz olan, ağrı toleransı düşük olan ve yaralanma korkusu yüksek olan hastalarda dizlik kullanımı tavsiye edilebilir. Dizlikteki ekstansiyon açısı $0^{\circ}$ olacak şekilde ayarlanır. Fleksiyon açısı ise rehabilitasyondaki ilerlemeye bağı olarak artırılır. Dizlik kullanım süresi hastanın durumuna göre değişebilmekte ve genelde cerrahi sonrası altı hafta dizlik kullanması önerilmektedir.

\section{NORMAL EKLEM HAREKETi}

Erken eklem hareket açıklığının kazanımı ağrıyı azaltmada, kıkırdağın homeostazisini düzenlemede ve patellofemoral eklem problemlerinin engellenmesinde önemlidir. Cerrahi sonrası ilk hafta diz fleksiyon eklem açıklığındaki hedef $90^{\circ}$ 'dir. Fleksiyon eklem hareket açıklığı yatarken veya otururken pasif ve aktif olarak çalıştırılabilir (Şekil 1 ve 2). Egzersizler ağrı sınırına kadar yapılmadır. Bunun yanında duvarda topuk kaydırma ve yüzükoyun yatarak diz fleksiyon egzersizleri de eklem hareket açıklığını artırmak için kullanılabilir. Diz fleksiyonu 4. haftaya doğru $120^{\circ}$, 6. haftanın sonuna gelindiğinde ise $135^{\circ}$ olmalıdır.

Tam diz ekstansiyonu cerrahi sonrasında hemen kazanılmalıdır çünkü ekstansiyon hareketindeki kısıtlılık (limitasyon) interkondiller çentikte ve posterior kapsülde aşırı skar oluşumuna neden olmaktadır. ${ }^{[11]}$ Bunun yanında, ekstansiyondaki kayıp kuadriseps kas aktivitesinin yetersiz olmasına, yürüyüş ve koşu mekaniğinde bozulmalara ve ileri dönem osteoartrit geliş̧me riskinde artışa neden olmaktadır. Tam diz ekstansiyonunun kazanımı 2. haftanın sonuna kadar sağlanamazsa germe egzersizleri programa dahil edilmelidir. 


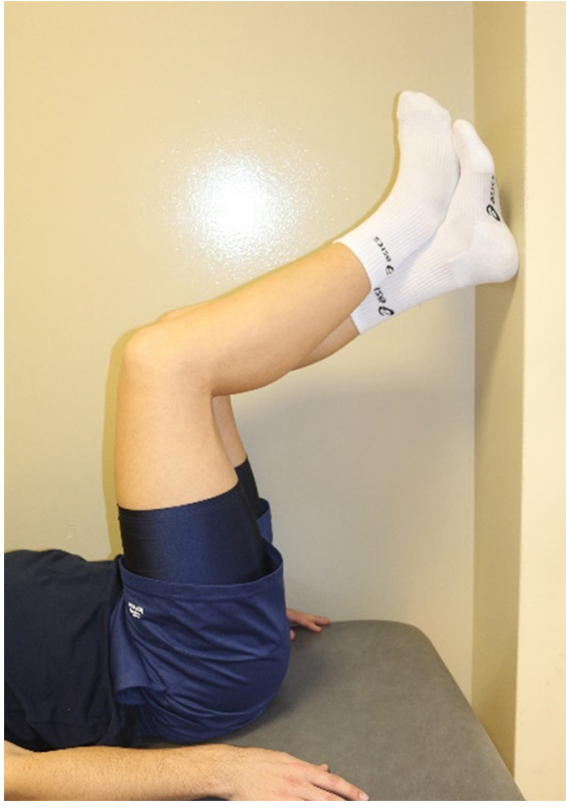

Şekil 1. Duvarda topuk kaydırma.

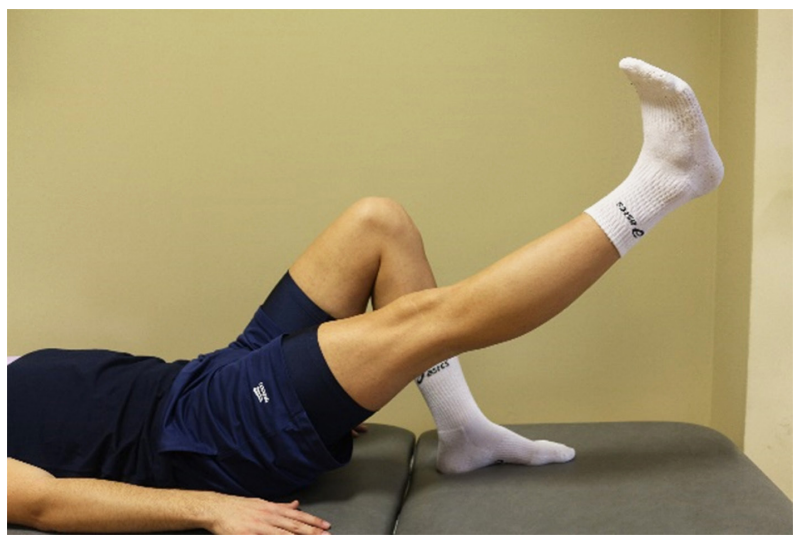

Şekil 3. Düz bacak kaldırma egzersizi.

\section{AĞIRLIK AKTARMA}

İzole ÖÇB rekonstrüksiyonundan sonra hastaların ekstremitesine tam ağırlık vermesi önerilebilmektedir. Ağılık aktarımı sırasında dizde tam ekstansiyonun sağlanmasına ve ekstremitelere eşit ağırlık verilmesine dikkat edilmelidir. ${ }^{[12]}$ Ağılık aktarma eğitiminin yumuşak zeminde yapılması propriyoseptif girdiyi artırma açısından tercih edilebilir. ÖÇB rekonstrüksiyonuna eşlik eden menisküs veya kıkırdak tamirlerinde ağırlık aktarımında yavaş ilerlemek gerekmektedir. Önce parsiyel olarak ağırlık aktarımına başlanılmalı, hastanın toleransına göre tam ağılık aktarımı cerrahi sonrası 4-6 haftalar arasında olmalıdır.

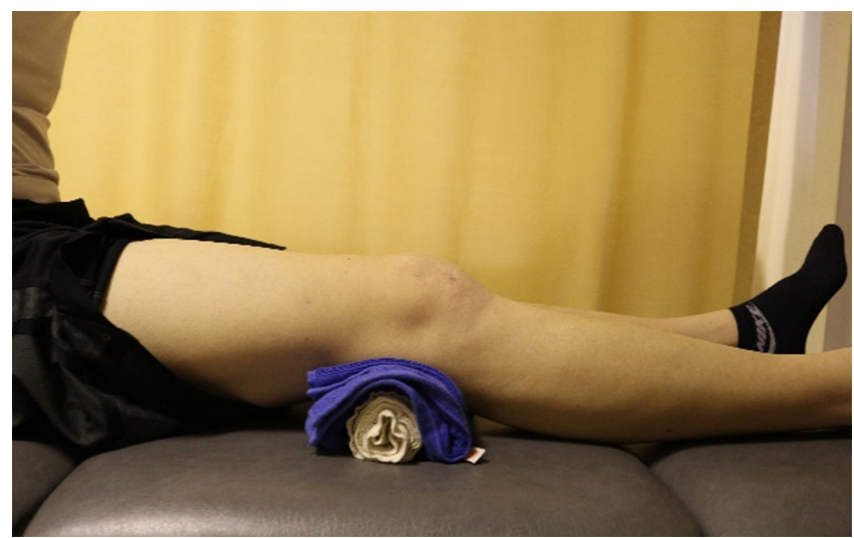

Şekil 4. Terminal izometrik egzersizi.

\section{NÖROMUSKÜLER EĞiTIM}

Nöromusküler eğitim kas kuvvetlendirme, propriyoseptif eğitim, denge ve pertürbasyon eğitimi, pliyometrik eğitim ve çeviklik eğitimini içermektedir. Kuvvetlendirme egzersizlerine cerrahi sonrası 1. günde başlanır. Kuadriseps kas kuvvetini artırmak için erken dönemde düz bacak kaldırma ve terminal izometrik egzersizleri yapılabilir (Şekil 3 ve 4). İzole hamstring kas kuvvetlendirme egzersizleri hamstring tendon otogrefti kullanılan hastalarda donör sahaya aşırı stres uygulayabileceğinden daha geç başlanmalıdır.

Kuadriseps kasının re-aktivasyonu sağlandıktan sonra, izometrik egzersizlerin sayısı azaltılarak konsantrik ve eksentrik kontraksiyonları içeren kapalı kinetik halka $(\mathrm{KKH})$ ve açık kinetik halka $(\mathrm{AKH})$ egzersizlerine ağırlık verilmelidir. ${ }^{[13]} \mathrm{KKH}$ egzersizleri ekstremite üzerine ağırlık aktarımının kontrolü sağlandıktan sonra başlanabilir (yaklaşık cerrahi sonrası 


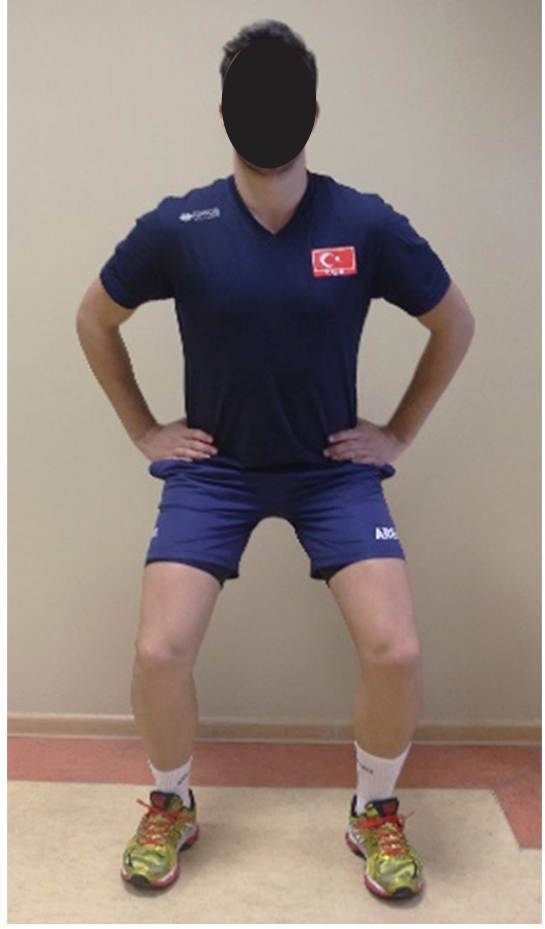

Şekil 5. Çömelme (squat).

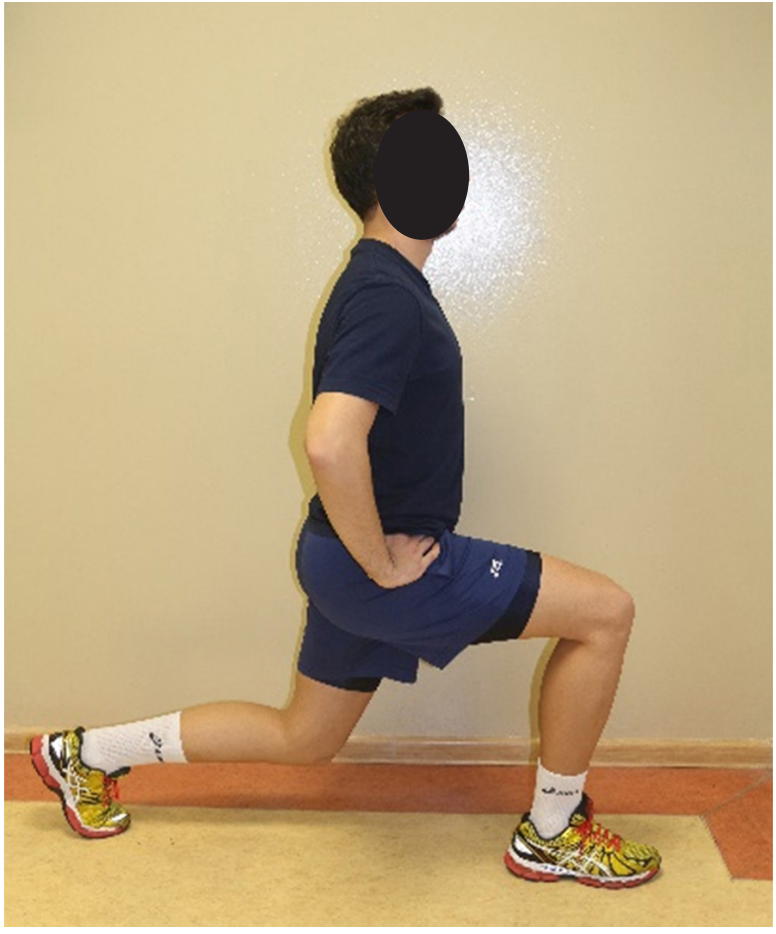

Şekil 6. Hamle (lunge).
2. hafta). KKH egzersizleri iyileşmekte olan grefte az stres uyguladığından, eklem stabilitesini geliştirdiğinden (hamstring ve kuadriseps ko-kontraksiyonu) ve fonksiyonel aktivitelere daha çok benzediğinden cerrahi sonrası erken dönemde AKH egzersizlerine kıyasla daha fazla tercih edilmektedir. Çömelme (squat), hamle (lunge), leg press ve basamak egzersizleri en fazla kullanılan KKH egzersizleridir (Şekil 5 ve 6). Egzersizler önce $0^{\circ}-30^{\circ}$ diz fleksiyonu ile başlanmalı ve semptomlar da göz önünde bulundurularak $60^{\circ}$ 'ye kadar ilerlenmelidir. KKH egzersizlerinde gluteus maksimus ve medius kaslarının aktivasyonunu artırarak core stabilite ve alt ekstremite düzgünlügüunün geliştirilmesi hedeflenir.

Kuadriseps AKH egzersizlerinin anterior tibial translasyon ile greft üzerine aşıı stres uygulaması erken dönemde ( $<4$ hafta) bu egzersizlerin tercih edilmemesine neden olmaktadır. ${ }^{[14]}$ Diğer yandan, $\mathrm{AKH}$ egzersizleri kuadriseps kasının izole olarak kurvetlendirilmesinde etkili olduğundan, güvenli diz eklem hareket açıklığında yapılması da önemlidir. Diz ekstansiyon egzersizine $90^{\circ}-45^{\circ}$ diz fleksiyon/ekstansiyon hareket açıklığında, cerrahi sonrası 4. haftadan itibaren, önce dirençsiz olacak şekilde başlanabilir. Allogreft veya hamstring tendon otogrefti ile ÖÇB rekonstrüksiyonu sonrası greftte elongasyonu önlemek için ilk üç ayda dirençsiz olarak diz ekstansiyon egzersizi yapılmalıdır. ${ }^{[15]}$ Son dönemlerde kuadriseps kas kuvvetinin geliştirilmesinde etkili olduğu düşünülen kontralateral eğitim[ ${ }^{[16]}$, kas akımı kısıtlamalı eğitim ${ }^{[17]}$ ve eksentrik eğitimler ${ }^{[18]}$ rehabilitasyon programları içerisinde yerini almaktadır. Bu eğitimlerle kuadriseps kas kuwvetindeki artışın daha hızlı bir şekilde olduğu kaydedilmiştir.

İzole dirençli hamstring kuvvetlendirme (leg curl) hamstring tendon greftinde cerrahiden sonra sekiz haftada başlanabilir (Şekil 7). Diğer greft tiplerinde ise 4. haftadan itibaren başlanabilir. Hamstring kası ÖÇB'nin sinerjisti olduğundan, hamstring kasının en kısa sürede kuvvetlendirilmesi greft üzerine etkiyen kuvvetlerin karşılanmasında önem taşımaktadır.

\section{YÜRÜYÜŞ, DENGE VE PROPRIOSEPTIF EĞiTiMi}

Ameliyat olmuş ekstremiteye ağırlık aktarma eğitimi tamamlandıktan sonra normal yürüyüş paterninin geri kazandırılması için en erken dönemde yürüyüş eğitimine başlanmalıdır. Yürüyüş eğitimi sırasında hastanın simetrik ağılık aktarımı ve yürüyüş fazlarının aynı sürede gerçekleştirilip gerçekleştirilmediğine dikkat etmek gerekir. Hastalar genelde diz ve kalça fleksiyonu 


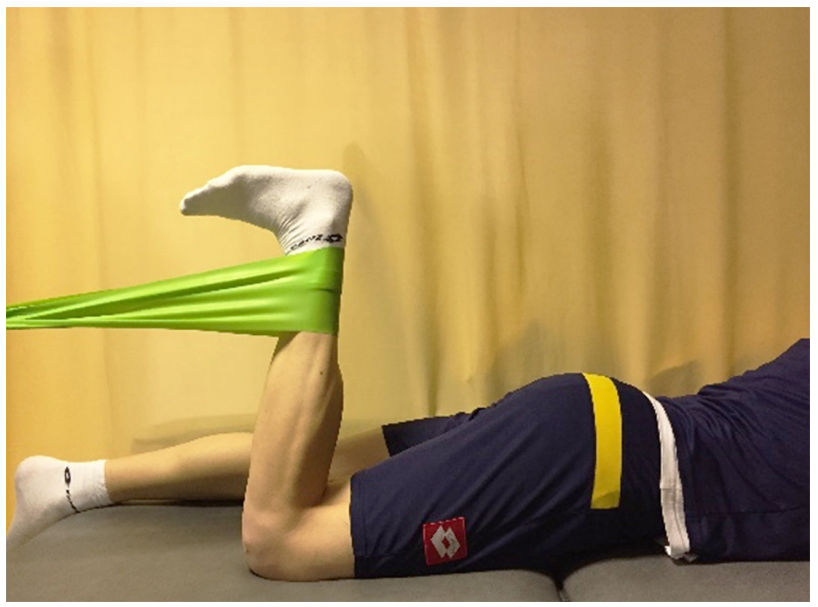

Şekil 7. Dirençli diz fleksiyon egzersizi.

yapmadan, dizlerini ekstansiyonda kilitleyerek, taban temasıyla yürümeye çalışırlar. Yürüyüş eğitimi önce normal zeminde daha sonra yumuşak zeminde gözler açık ve kapalı olacak şekilde yapılabilir.

Denge ve pertürbasyon eğitiminde stabil olmayan denge platformları veya dışardan uygulanan pertürbasyonla dinamik diz kontrolünün geliştirilmesi için bilinçdışı motor cevapların eğitimi hedeflenir. Egzersizlerde önce iki bacak ile başlanır, daha sonra tek bacağa doğru ilerlenir. Gözler açık-kapalı olmasına ve denge platformlarının zorluk derecesine göre eğitimler planlanır. Yapılan spora göre, egzersizlerin uyarlanması fonksiyonel rehabilitasyon açısından önemlidir.

\section{PLIYOMETRIK EĞіTIM}

Pliyometrik eğitime başlamak için diz ekstansiyon ve fleksiyon hareketi sağlam tarafla aynı olması beklenir. Kuadriseps kas kuvvetinin sağlam tarafa göre en az $\% 60$, hamstring kas kuvvetinin ise $\% 80$ ve üzeri olması beklenir. Pliyometrik egzersizlerin fazları düşünüldüğünde (eksentrik-amortizasyon-konsantrik) hastanın özellikle kuadriseps kasının konsantrik, izometrik ve eksentrik kasılma kontrolünün bu eğitim için yeterli olması gereklidir. ${ }^{[19]}$ ÖÇB yaralanma nedenlerinden birisinin sıçrama sonrası düşüşteki dizdeki valgus kollapsı olduğu düşünüldüğünde, pliyometrik eğitimin tekrar yaralanmaların önüne geçilmesinde çok önemli rol oynadığı bilinmelidir. Bu eğitimde, hastalara doğru sıçrama ve sıçrama sonrası düşüş tekniği öğretir. Bu eğitimler sırasında hastalar korku duyabilmektedir. Bu nedenle eğitime öncelikle çift bacak ve küçük açılarda başlanır.
Pliyometrik eğitimde dikkat edilecek noktalar ${ }^{[19,20]}$ :

1. Sıçrama ve sıçrama sonrası düşüşte kalça ve diz fleksiyonunun yeterli olmasına dikkat edilmelidir.

2. Sıçrama sonrası düşüşte dizde aşırı valgus hareketinin oluşması engellenmelidir.

3. Hastanın sıçrama başında ve yere temasında ekstremitelerine eşit ağırlık vermesi sağlanmalıdır.

4. Sıçramalara önce çift ayak küçük açılarla ve noktada başlanmalıdır. Daha sonra öne, yana ve arkaya sıçramalarla eğitim zorlaştırılmalıdır. Alt ekstremite düzgünlüğünün sağlandığından emin olunduktan sonra yumuşak zeminlerde ve trombolinde eğitimlere devam edilebilir. Tek ayak sıçramalar da aynı protokolde devam ettirilir.

\section{KOŞU VE ÇEVIKLIK EĞiTiMi}

Koşu programına yavaş tempoda (jogging) başlanır. Koşu eğitiminde ekstremite simetrisi, kalça ve diz fleksiyonu simetrisi, dizdeki sertlik (stiffness) parametrelerine dikkat edilmelidir. Koşu programı haftanın üç günü, kuvvetlendirme eğitiminin olmadığı günlerde yapılmalıdır. Öncelikle düz öne koşu eğitimine başlanır. Koşu mesafesi düzenli olarak artırılarak hastanın kondisyonu artırılır. Hasta normal hızda öne koşuları başardığında, normal hızda yana koşular ve çapraz koşular başlatılır. Bu eğitimde çevikliğe de odaklanılır. Son olarak geriye koşular başlatılır. Geri koşularda hastanın vücut düzgünlüğün sağlanmasına dikkat edilmelidir. Yanlış vücut postürü düşmelere neden olabilmektedir. Çeviklik eğitimi içinde sekiz şekilli koşular, karaoke koşu, yan ve çapraz koşulara yer verilir. Hastanın normal hızdaki koşu süresi artırılmaya çalışılır.

Spora özgü eğitime başlamadan önce, dizde ağrı ve effüzyonun olmaması veya minimal olması, eklem hareket açıkığında limitasyonun olmaması, izokinetik test sonucu yaralanmış tarafin kuadriseps ve hamstring kas kuvvet kaybının \%20'den fazla olmaması, sıçrama performansındaki kaybının \%10'dan fazla olmaması ve sporcunun koşu bandında $8 \mathrm{~km} / \mathrm{saat}$ hızında en az 10 dakika (dk) koşabilmesi gereklidir. ${ }^{[21]}$

\section{SPORA DÖNÜŞ}

ÖÇB rekonstrüksiyonu sonrası spora dönüş oranı 1. yılda \%50 iken, 2. yılda \%70 civarındadır. Bunun yanında spora dönüş yapan bireylerde ikincil ÖÇB yaralanma oranının \%35'e kadar çıktığı gösterilmiştir. ${ }^{[22,23]}$ Bundan dolayı, özellikle spora dönüş sonrası ikincil yaralanmaların önlenmesi açısından rehabilitasyonun son aşamasında spora dönüş test bataryası oluşturulmuştur. Son yapılan meta-analiz çalışmasında, spora dönüş kriterlerini tamamlayarak spora dönen 
bireylerin greft rüptür riskinin daha az olduğu fakat kontralateral tarafta ÖÇB yaralanma riskinin daha fazla olduğu bulunmuştur. ${ }^{[24]}$

ÖÇB rekonstrüksiyonu sonrası spora dönüşe objektif performansa dayalı testler (kas kuvveti, denge, sıçrama), subjektif skorlar (diz fonksiyonu ve kinezyofobiyi değerlendiren anketler) ve klinik muayene (laksite, ağrı, ödem vb.) ile karar verilmektedir.

Spora dönüş kriterleri ${ }^{[3,25,26]}$ :

\section{Diz ekleminde ağrı ve effüzyonun olmaması}

2. Fiziksel aktivite ile birlikte diz ekleminde ödem oluşmaması

3. Dizin normal eklem hareketinin tam olması veya diz fleksiyonunda $5^{\circ}$ 'den az kayıp

4. Anterior laksitenin $3 \mathrm{~mm}$ 'den az olması (KT 1000/2000)

5. Kuadriseps ve hamstring kas kuvvetinin karşı taraf kas kurvetinin en az \%90'nında olması (Temas sporunda \%100 olması)

6. Sıçrama testlerinde (öne sıçrama, üç adım sıçrama, çapraz sıçrama ve altı metre sıçrama) ekstremite simetrisinin en az $\% 90$ olması

7. IKDC skorundan 95 ve üzeri almak, KOOS skorunun $\% 90$ 'dan fazla olması

8. ACL-RSI (Anterior Cruciate Ligament Return to Sport After Injury) skorundan en az 60 puan almak (bireyin psikolojik olarak hazır olması)

\section{KAYNAKLAR}

1. Grindem H, Snyder-Mackler L, Moksnes H, Engebretsen L, Risberg MA. Simple decision rules can reduce reinjury risk by $84 \%$ after ACL reconstruction: The Delaware-Oslo ACL cohort study. Br J Sports Med 2016;50(13):804-8. Crossref

2. van Grinsven $S$, van Cingel RE, Holla CJ, van Loon CJ. Evidence-based rehabilitation following anterior cruciate ligament reconstruction. Knee Surg Sports Traumatol Arthrosc 2010;18(8):1128-44. Crossref

3. van Melick $N$, van Cingel RE, Brooijmans F, Neeter C, van Tienen T, Hullegie W, Nijhuis-van der Sanden MWG. Evidence-based clinical practice update: practice guidelines for anterior cruciate ligament rehabilitation based on a systematic review and multidisciplinary consensus. Br J Sports Med 2016;50(24):1506-15. Crossref

4. de Valk EJ, Moen MH, Winters M, Bakker EW, Tamminga R, van der Hoeven $\mathrm{H}$. Preoperative patient and injury factors of successful rehabilitation after anterior cruciate ligament reconstruction with single-bundle techniques. Arthroscopy 2013;29(11):1879-95. Crossref

5. Grindem H, Granan LP, Risberg MA, Engebretsen L, SnyderMackler L, Eitzen I. How does a combined preoperative and postoperative rehabilitation programme influence the outcome of $A C L$ reconstruction 2 years after surgery? A comparison between patients in the Delaware-Oslo $\mathrm{ACL}$ Cohort and the Norwegian National Knee Ligament Registry. Br J Sports Med 2015;49(6):385-9. Crossref
6. Shaerf DA, Pastides PS, Sarraf KM, Willis-Owen CA. Anterior cruciate ligament reconstruction best practice: A review of graft choice. World J Orthop 2014;5(1):23-9. Crossref

7. Martimbianco AL, Gomes da Silva BN, de Carvalho AP, Silva V, Torloni MR, Peccin MS. Effectiveness and safety of cryotherapy after arthroscopic anterior cruciate ligament reconstruction. A systematic review of the literature. Phys Ther Sport 2014;15(4):261-8. Crossref

8. Young A. Current issues in arthrogenous inhibition. Ann Rheum Dis 1993;52(11):829-34. Crossref

9. Kim KM, Croy T, Hertel J, Saliba S. Effects of neuromuscular electrical stimulation after anterior cruciate ligament reconstruction on quadriceps strength, function, and patientoriented outcomes: a systematic review. J Orthop Sports Phys Ther 2010;40(7):383-91. Crossref

10. Lobb R, Tumilty S, Claydon LS. A review of systematic reviews on anterior cruciate ligament reconstruction rehabilitation. Phys Ther Sport 2012;13(4):270-8. Crossref

11. Shelbourne KD, Urch SE, Gray T, Freeman H. Loss of normal knee motion after anterior cruciate ligament reconstruction is associated with radiographic arthritic changes after surgery. Am J Sports Med 2012;40(1):108-13. Crossref

12. Tyler TF, McHugh MP, Gleim GW, Nicholas SJ. The effect of immediate weightbearing after anterior cruciate ligament reconstruction. Clin Orthop Relat Res 1998;357:141-8. Crossref

13. Harput G, Kilinc HE, Ozer $H$, Baltaci G, Mattacola CG. Quadriceps and Hamstring Strength Recovery During Early Neuromuscular Rehabilitation After ACL Hamstring-Tendon Autograft Reconstruction. J Sport Rehabil 2015;24(4):398404. Crossref

14. Escamilla RF, Macleod TD, Wilk KE, Paulos L, Andrews JR. Anterior cruciate ligament strain and tensile forces for weightbearing and non-weight-bearing exercises: a guide to exercise selection. J Orthop Sports Phys Ther 2012;42(3):208-20. Crossref

15. Fukuda TY, Fingerhut D, Moreira VC, Camarini PMF, Scodeller NF, Duarte A, Jr., Duarte A, Martinelli M, Bryk FF. Open kinetic chain exercises in a restricted range of motion after anterior cruciate ligament reconstruction: a randomized controlled clinical trial. Am J Sports Med 2013;41(4):78894. Crossref

16. Harput G, Ulusoy B, Yildiz TI, Demirci S, Eraslan L, Turhan E, Tunay VB. Cross-education improves quadriceps strength recovery after $A C L$ reconstruction: a randomized controlled trial. Knee Surg Sports Traumatol Arthrosc 2019;27(1):6875. Crossref

17. Lipker LA, Persinger CR, Michalko BS, Durall CJ. Blood Flow Restriction Therapy Versus Standard Care for Reducing Quadriceps Atrophy After Anterior Cruciate Ligament Reconstruction. J Sport Rehabil 2019;28(8):897-901. Crossref

18. Gokeler A, Bisschop M, Benjaminse A, Myer GD, Eppinga P, Otten E. Quadriceps function following ACL reconstruction and rehabilitation: implications for optimisation of current practices. Knee Surg Sports Traumatol Arthrosc 2014;22(5):1163-74. Crossref

19. Hewett TE, Di Stasi SL, Myer GD. Current concepts for injury prevention in athletes after anterior cruciate ligament reconstruction. Am J Sports Med 2013;41(1):216-24. Crossref

20. Sugimoto D, Myer GD, Foss KD, Hewett TE. Specific exercise effects of preventive neuromuscular training intervention on anterior cruciate ligament injury risk reduction in young females: meta-analysis and subgroup analysis. Br J Sports Med 2015;49(5):282-9. Crossref 
21. Mithoefer K, Hambly K, Logerstedt D, Ricci M, Silvers $H$, Della Villa S. Current concepts for rehabilitation and return to sport after knee articular cartilage repair in the athlete. J Orthop Sports Phys Ther 2012;42(3):254-73. Crossref

22. Ardern CL, Taylor NF, Feller JA, Webster KE. Fifty-five per cent return to competitive sport following anterior cruciate ligament reconstruction surgery: an updated systematic review and meta-analysis including aspects of physical functioning and contextual factors. Br J Sports Med 2014;48(21):154352. Crossref

23. Ardern CL, Webster KE, Taylor NF, Feller JA. Return to sport following anterior cruciate ligament reconstruction surgery: a systematic review and meta-analysis of the state of play. $\mathrm{Br} \mathrm{J}$ Sports Med 2011;45(7):596-606. Crossref
24. Webster KE, Hewett TE. What is the Evidence for and Validity of Return-to-Sport Testing after Anterior Cruciate Ligament Reconstruction Surgery? A Systematic Review and MetaAnalysis. Sports Med 2019;49(6):917-29. Crossref

25. Davies GJ, McCarty E, Provencher M, Manske RC. ACL Return to Sport Guidelines and Criteria. Curr Rev Musculoskelet Med 2017;10(3):307-14. Crossref

26. Webster KE, Feller JA. A research update on the state of play for return to sport after anterior cruciate ligament reconstruction. J Orthop Traumatol 2019;20(1):10. Crossref 